\title{
Regulation of the Plasmid-specified Naphthalene Catabolic Pathway of Pseudomonas putida
}

\author{
By R. A. AUSTEN AND N. W. DUNN \\ School of Biological Technology, University of New South Wales, \\ P.O. Box 1, Kensington, New South Wales, Australia 2033
}

(Received 28 August 1979; revised 7 December 1979)

\begin{abstract}
The regulation of the catabolic pathway for the degradation of naphthalene specified by the plasmids NAH, pND140 and pND160 was studied using plasmid-borne regulatory mutants in a Pseudomonas putida host strain. Growth of strains harbouring the parent plasmids in the presence of salicylate resulted in induction of selected enzymes involved in the conversion of naphthalene to catechol (naphthalene oxygenase, salicylaldehyde dehydrogenase and salicylate hydroxylase) and enzymes of the meta-cleavage pathway (catechol 2,3-dioxygenase, 2-hydroxymuconic semialdehyde hydrolase and 2-hydroxymuconic semialdehyde dehydrogenase). Partial induction was also observed for all the NAH-encoded enzymes assayed when using $m$-toluate as the inducing compound, over a genetic block. Mutants were obtained for each plasmid where the three enzymes of the meta-cleavage pathway were produced constitutively suggesting that the enzymes of the meta-cleavage pathway belong to one operon. In these mutants, enzymes involved in the conversion of naphthalene to catechol were not produced constitutively but remained inducible during growth on salicylate indicating that these enzymes belong to a separate operon or operons.
\end{abstract}

\section{INTRODUCTION}

The pathway for the degradation of naphthalene found in several pseudomonads is outlined in Fig. 1. Naphthalene is degraded to catechol, and all three plasmids studied in this work, NAH (Dunn \& Gunsalus, 1973) and pND140 and pND160 (Dunn et al., 1980), encode the meta-cleavage pathway for the subsequent metabolism of catechol. In some other naphthalene-utilizing strains which possess this same pathway no evidence has been obtained to implicate plasmids. Many of the naphthalene-utilizing strains which have the metacleavage pathway for catechol breakdown also have the ortho-cleavage pathway. In strains which have both pathways for the degradation of catechol, the route of catechol metabolism depends on the relative induction of each pathway (Davies \& Evans, 1964; Catterall et al., $1971 a, b$; Jerina et al., 1971; Barnsley, $1976 a, b)$.

There are at present few published results concerning the regulation of the plasmidencoded naphthalene catabolic pathway. It has been reported that in Pseudomonas putida strain PpG7 (ATCC 17485), which harbours the NAH plasmid, salicylate is the inducer of the enzymes which convert naphthalene to catechol and of the enzymes of the meta-cleavage pathway for catechol (Barnsley, 1975, 1976a). The possibility was suggested that all the enzymes involved in the catabolism of naphthalene are regulated as a unit in strain PpG7.

The present paper describes aspects of the regulation of the naphthalene catabolic pathways encoded by plasmids NAH, pND140 and pND160 and describes properties of some regulatory mutants of these plasmids. 


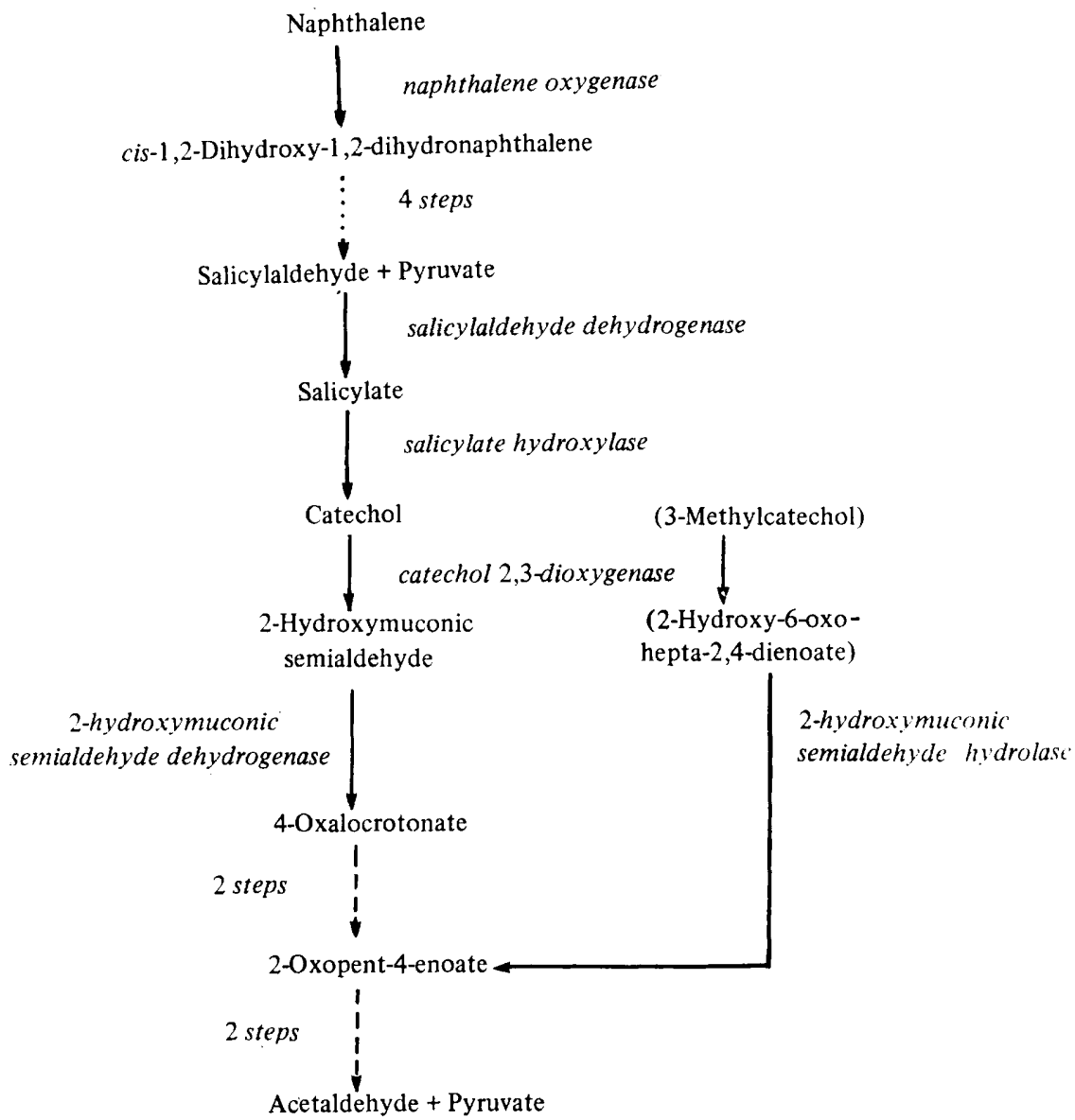

Fig. 1. Outline of the plasmid-encoded naphthalene catabolic pathway. The plasmid-encoded catechol 2,3-dioxygenase has a broad specificity and, in addition to the conversion of catechol to 2-hydroxymuconic semialdehyde, it is able to convert 3-methylcatechol to 2-hydroxy-6-oxohepta2,4 -dienoate. These two compounds are then degraded by different mechanisms within the metacleavage pathway.

\section{METHODS}

Bacterial strains and plasmids. The bacteria and plasmids, listed in Table 1, were handled as previously described (Dunn \& Gunsalus, 1973; Austen \& Dunn, 1977a; White \& Dunn, 1977; Dunn et al., 1980).

Isolation of spontaneous plasmid mutants. Six large colonies of PP1-3(pND140) and PP1-3(pND160) from PAS plus benzoate growth response plates (Dunn et al., 1980) were purified by single colony isolation on benzoate and then tested for growth on several aromatic substrates (see Table 2). All had gained the ability to grow well on benzoate and phenol but still could not grow on $m$-toluate. One mutant derived from pND140 and one from pND160 were retained for further study and were designated pND141 and pND161, respectively.

Culture conditions for organisms used in enzyme assays. The minimal salts medium was PAS (Chakrabarty, 1972). Cultures were grown overnight at $30^{\circ} \mathrm{C}$ with shaking in PAS plus $10 \mathrm{~mm}$-acetate plus $5 \mathrm{~mm}$-succinate and then added as a $25 \%(\mathrm{v} / \mathrm{v})$ inoculum to PAS plus $10 \mathrm{~mm}$-acetate plus $5 \mathrm{~mm}$ inducer or PAS plus $15 \mathrm{~mm}$ acetate plus $5 \mathrm{~mm}$ inducer (induction over a genetic block) or PAS plus $15 \mathrm{~mm}$-acetate (no inducer). The latter cultures were incubated at $30^{\circ} \mathrm{C}$ with shaking for $3.5 \mathrm{~h}$ prior to assay of catechol 2,3-dioxygenase, 2-hydroxymuconic semialdehyde dehydrogenase and 2-hydroxymuconic semialdehyde hydrolase and for $6 \mathrm{~h}$ prior to assay of naphthalene oxygenase, salicylaldehyde dehydrogenase, salicylate hydroxylase and catechol 2,3-dioxygenase. These induction conditions were chosen following a study of primary growth substrates, inducers and induction periods. No diauxic growth curves or catabolite repression of the enzymes studied in the naphthalene catabolic pathway were observed when using acetate as the primary growth substrate. 


\section{Table 1. Bacterial strains and plasmids}

Strains of Pseudomonas putida*

\begin{tabular}{|c|c|c|}
\hline PP1-2 & wild-type & Wong \& Dunn (1974) \\
\hline PP1-3 & ben-1 & Wong is Dunn (1974) \\
\hline PP1-10 & ben-2 & Austen \& Dunn (1977a) \\
\hline \multicolumn{3}{|c|}{ Catabolic plasmids } \\
\hline NAH & \multirow{4}{*}{\multicolumn{2}{|c|}{$\begin{array}{l}\text { Dunn \& Gunsalus (1973) } \\
\text { NAH control mutant (Austen \& Dunn, 1977 b) } \\
\text { NAH control mutant (Austen \& Dunn, 1977 b) } \\
\text { New plasmid specifying naphthalene degradation } \\
\quad \text { (Dunn et al., 1980) }\end{array}$}} \\
\hline pND110 & & \\
\hline pND111 & & \\
\hline pND140 & & \\
\hline pND141 & \multicolumn{2}{|c|}{ pND140 control mutant } \\
\hline pND160 & \multicolumn{2}{|c|}{$\begin{array}{l}\text { New plasmid specifying naphthalene degradation } \\
\text { (Dunn et al., 1980) }\end{array}$} \\
\hline pND161 & \multicolumn{2}{|c|}{ pND160 control mutant } \\
\hline TOL & \multicolumn{2}{|c|}{ Williams \& Murray (1974); Wong \& Dunn (1974) } \\
\hline
\end{tabular}

* The parental bacterial host strain (PP1-2) can convert phenol and benzoate to catechol independently and catechol is then degraded by the ortho-cleavage pathway. The enzyme system responsible for conversion of benzoate to catechol is also able to convert $m$-toluate to 3-rnethylcatechol; however, 3-methylcatechol cannot be further metabolized through the ortho-cleavage pathway (Austen \& Dunn, 1977a). Strain PP1-3 is defective in catechol 1,2-dioxygenase, the first enzyme of the ortho-cleavage pathway; PP1-10 is defective in the conversion of benzoate to catechol.

Preparation of extracts used in assays of salicylaldehyde dehydrogenase, salicylate hydroxylase and catechol 2,3-dioxygenase. Bacteria were harvested by centrifuging at $2{ }^{\circ} \mathrm{C}$, washed twice with cold $50 \mathrm{~mm}$-sodium phosphate buffer ( $\mathrm{pH} 7 \cdot 0$ ) and resuspended at a concentration of about $0.1 \mathrm{~g}$ wet wt $\mathrm{ml}^{-1}$ in similar buffer. This suspension $(5 \mathrm{ml})$ was disrupted at $2{ }^{\circ} \mathrm{C}$ using three $1 \mathrm{~min}$ treatments with a Bronwill Sonic Oscillator model B1OIV using the needle probe at the LO 80 setting. Cell debris was removed by centrifuging at $39000 \mathrm{~g}$ for $1 \mathrm{~h}$ at $4{ }^{\circ} \mathrm{C}$ (Barnsley, 1975).

Preparation of extracts used in assays of enzymes of the meta-cleavage pathway for catechol. Bacteria were harvested by centrifuging at $2{ }^{\circ} \mathrm{C}$, washed twice with cold $0.85 \%(\mathrm{w} / \mathrm{v}) \mathrm{KCl}$, resuspended in $4 \mathrm{ml}$ cold $50 \mathrm{~mm}$ phosphate buffer $(\mathrm{pH} 7 \cdot 5)$ containing acetone $(10 \%, \mathrm{v} / \mathrm{v})$, and disrupted by sonication at $2{ }^{\circ} \mathrm{C}$ using three $1 \mathrm{~min}$ treatments as above. Cell debris was removed by centrifuging at $12000 \mathrm{~g}$ for $10 \mathrm{~min}$ at $2^{\circ} \mathrm{C}$ (Austen \& Dunn, 1977a).

Preparation of 2-hydroxymuconic semialdehyde and 2-hydrcxy-6-oxohepta-2,4-dienoate. Catechol 2,3dioxygenase was purified (as far as the first crystallization) from benzoate-induced PP1-3 (TOL) using the method described by Nozaki et al. (1963). A sample $(0.2 \mathrm{ml})$ of the purified catechol 2,3-dioxygenase in 0.05 mM-phosphate buffer ( $\mathrm{pH} 7 \cdot 5)$ containing acetone $(10 \%, \mathrm{v} / \mathrm{v}$ ) was added to $3 \mu \mathrm{mol}$ catechol or 3-methylcatechol and $280 \mu \mathrm{mol}$ sodium phosphate buffer $(\mathrm{pH} \mathrm{7.0)}$ in a total volume of $3 \mathrm{ml}$. The solutions were shaken intermittently at ambient temperature for $10 \mathrm{~min}$ and then kept in ice and used the same day. The $0.2 \mathrm{ml}$ sample of catechol 2,3-dioxygenase contained sufficient activity to oxidize $20 \mu \mathrm{mol}$ catechol min ${ }^{-1}$.

$N A D$ glycohydrolase treatment. Extract $(1 \mathrm{ml})$ was incubated for $1 \mathrm{~h}$ with $3.5 \mathrm{mg}$ NAD glycohydrolase (Sigma) at ambient temperature and then centrifuged at $5000 \mathrm{~g}$ for $5 \mathrm{~min}$ at $4{ }^{\circ} \mathrm{C}$. The supernatant was kept in ice and used the same day. This method is similar to that used by Sala-Trepat et al. (1972).

Protein and dry weight determinations. Protein was estimated using the Lowry method with bovine serum albumin as the standard. Dry weights were determined by evapcrating samples $(5 \mathrm{ml})$ of the washed wholecell suspension to dryness in a hot air oven at $105^{\circ} \mathrm{C}$ and corresting for buffer residue weights.

Enzyme assays. All spectrophotometric assays were done at $20^{\circ} \mathrm{C}$ using silica cuvettes $(1 \mathrm{~cm}$ light path) in a recording spectrophotometer. All extracts and cell suspensions were used during the day on which they were prepared.

Naphthalene oxygenase was measured spectrophotometrically (Shamsuzzaman \& Barnsley, 1974a) using whole cells. The absorption coefficient of naphthalene at $276 \mathrm{~nm}$ used in calculations of reaction rates was $45101 \mathrm{~mol}^{-1} \mathrm{~cm}^{-1}$ (not corrected for the presence of salicylate). The specific activities presented are therefore minimum values. One unit of activity is defined as that which converts $1 \mu \mathrm{mol}$ naphthalene $\mathrm{min}^{-1}$.

Salicylaldehyde dehydrogenase was assayed according to the method of Shamsuzzaman \& Barnsley



Salicylate hydroxylase (EC 1.14.13.1) was assayed according to the method of Barnsley (1975). One unit of enzyme activity is defined as that which oxidizes $1 \mu \mathrm{mol} \mathrm{NADH} \mathrm{min}^{-1}$. 
Catechol 2,3-dioxygenase (EC 1.13.11.2) was determined by measuring the rate of increase in absorbance at $375 \mathrm{~nm}$ due to conversion of catechol to 2-hydroxymuconic semialdehyde (Nozaki et al., 1963). The assay

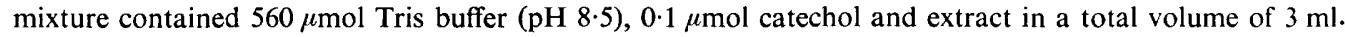
Conversion of $1 \mu \mathrm{mol}$ catechol to 2-hydroxymuconic semialdehyde at pH 8.5 causes an increase in $A_{375}$ of 12.4 (Austen \& Dunn, 1977a). One unit of enzyme activity is defined as that which converts $1 \mu$ mol catechol $\min ^{-1}$.

2-Hydroxymuconic semialdehyde dehydrogenase and 2-hydroxymuconic semialdehyde hydrolase were assayed at $\mathrm{pH} 8.0$ which is optimal for activity of the NAH-encoded enzymes. 2-Hydroxymuconic semialdehyde hydrolase activity was determined at $388 \mathrm{~nm}$ using 2-hydroxy-6-oxohepta-2,4-dienoate (the catechol 2,3-dioxygenase ring fission product of 3-methylcatechol) as substrate according to the method of Murray \& Williams (1974). 2-Hydroxymuconic semialdehyde dehydrogenase activity was determined by subtracting the rate of disappearance of 2-hydroxymuconic semialdehyde in an assay mixture which contained an extract treated with NAD glycohydrolase from the rate in an assay mixture which contained extract supplemented with NAD. The rate of 2-hydroxymuconic semialdehyde disappearance was determined by measuring the rate of decrease in $A_{375}$. The former assay mixture contained $280 \mu$ mol sodium phosphate buffer ( $\mathrm{pH} 8.0$ ), $0 \cdot 1 \mu \mathrm{mol} 2$-hydroxymuconic semialdehyde and extract treated with NAD glycohydrolase in a total volume of $3 \mathrm{ml}$. The latter assay mixture contained $280 \mu \mathrm{mol}$ sodium phosphate buffer $(\mathrm{pH} 8 \cdot 0), 0 \cdot 1 \mu$ mol 2-hydroxymuconic semialdehyde, $1 \mu \mathrm{mol}$ NAD and extract in a total volume of $3 \mathrm{ml}$ (Sala-Trepat et al., 1972). Conversion of $1 \mu \mathrm{mol}$ 2-hydroxy-6-oxohepta-2,4-dienoate and 2-hydroxymuconic semialdehyde causes decreases in $A_{388}$ and $A_{375}$ of $7 \cdot 1$ and $11 \cdot 7$, respectively. Units of enzyme activity are defined as the conversion of $1 \mu \mathrm{mol}$ substrate $\mathrm{min}^{-1}$.

\section{RESULTS AND DISCUSSION}

Plasmid-encoded mutations were used to study regulation within the naphthalene catabolic pathways encoded by NAH, pND140 and pND160. The isolation of two mutants of the NAH plasmid, pND110 and pND111, has been described by Austen \& Dunn $(1977 b)$. Plasmid pND110 specifies a catechol 2,3-dioxygenase with an altered inducer specificity and has lost the ability to utilize naphthalene. Plasmid pND111 encodes a catechol 2,3dioxygenase which appears to be produced constitutively.

Growth responses for PP1-2, PP1-3 and PP1-10 (Table 2) are in accordance with the strain characteristics described in Table 1. Strain PP1-3 harbouring the regulatory mutant pND111 acquired the ability to grow well on phenol and benzoate and to give improved growth on $m$-toluate; PP1-3(pND110) acquired the last two growth phenotypes. When growth is observed on phenol, benzoate or $m$-toluate in the absence of a functional orthocleavage pathway, the growth phenotypes are composite phenotypes; the host cell converts each compound to the corresponding catechol and then these are degraded via the plasmidencoded meta-cleavage pathway. Consequently PP1-10 harbouring these plasmids is unable to grow on benzoate or $m$-toluate and this can be useful as it permits the use of benzoate and $m$-toluate as inducers, over a genetic block. It also eliminates toxicity problems when a strain can convert benzoate or $m$-toluate to the corresponding catechol but cannot further catabolize these compounds.

The growth responses associated with residence of plasmids pND140 and pND160 in both PP1-3 and PP1-10 and mutant plasmids pND141 and pND161 in PP1-3 are given in Table 2. Plasmid-associated growth on benzoate, $m$-toluate and phenol required the use of the host cell-encoded ability to convert these substrates to catechol or 3-methylcatechol (Dunn et al., 1980). Comparison with the growth responses of PP1-3(pND140) and PP1-3(pND160) indicated that PP1-3(pND141) and PP1-3(pND161) had gained the ability to grow well on benzoate and phenol but, surprisingly, not on $m$-toluate. Assay of the pND141 and pND161-encoded catechol 2,3-dioxygenases indicated that the enzyme was produced constitutively and did not require the presence of aromatic inducers (Table 3 ). That is, the pND141 and pND161 mutants appeared to be similar to pND111.

The observation that a single mutation causes a change in the regulation of several enzymes simultaneously suggests that the genes which specify these enzymes may share a control element. Therefore, selected NAH, pND110, pND111, pND140, pND141, pND160 


\section{Table 2. Growth responses of $P$. putidc strains harbouring naphthalene catabolic plasmids}

Incubation was for $3 \mathrm{~d}$ at $30^{\circ} \mathrm{C}$. Responses were rated as follows: $4+$, colonies about $2 \mathrm{~mm}$ diam.; $3+, 1 \mathrm{~mm} ; 2+, 0.5 \mathrm{~mm} ;+, 0.1 \mathrm{~mm} ;-$, no growth. $L$ indicates that large colonies, at least $0.5 \mathrm{~mm}$ diam., appeared after 2 to $5 \mathrm{~d}$ incubation at a frequency of about $10^{-7}$ on benzoate or phenol or after about $8 \mathrm{~d}$ on $m$-toluate. B indicates a black or brown coloration of the medium after about $2 \mathrm{~d}$ incubation.

Growth response on substrate

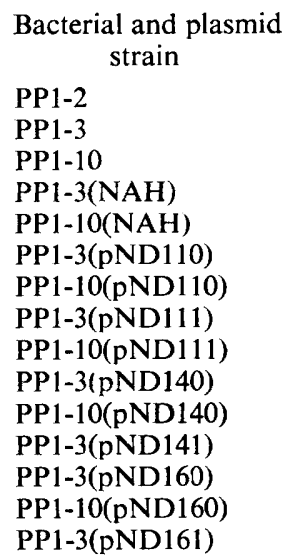

$\begin{array}{cccccc}\begin{array}{c}\text { Naphthalene } \\ \text { (vapour }\end{array} & \begin{array}{c}\text { Salicyl- } \\ \text { aldehyde }\end{array} & \begin{array}{c}\text { Salicylate } \\ (10 \mathrm{mM})\end{array} & \begin{array}{c}\text { Benzoate } \\ (10 \mathrm{mM})\end{array} & \begin{array}{c}m \text {-Toluate } \\ (10 \mathrm{mM})\end{array} & \begin{array}{c}\text { Phenol } \\ (2 \cdot 5 \mathrm{mM})\end{array} \\ \begin{array}{c}(2 \cdot 5 \mathrm{mM}) \\ \text { phase) }\end{array} & - & - & 4+ & -(\mathrm{B}) & 3+ \\ - & - & - & -(\mathrm{B}) & -(\mathrm{B}) & -(\mathrm{B}) \\ - & - & - & - & - & 3+ \\ 4+ & + & 4+ & -(\mathrm{B}) & + & -(\mathrm{B}, \mathrm{L}) \\ 4+ & + & 4+ & - & - & 3+ \\ - & - & 4+ & 3+(\mathrm{B}) & 2+ & -(\mathrm{B}, \mathrm{L}) \\ - & - & 4+ & - & - & 3+ \\ 4+ & + & 4+ & 3+(\mathrm{B}) & 2+ & 2+ \\ 4+ & + & 4+ & - & - & 3+ \\ 4+ & + & 4+ & -(\mathrm{B}, \mathrm{L}) & -(\mathrm{B}) & -(\mathrm{B}, \mathrm{L}) \\ 4+ & + & 4+ & - & - & 3+ \\ 4+ & + & 4+ & 4+ & -(\mathrm{B}, \mathrm{L}) & 3+ \\ 4+ & + & 4+ & -(\mathrm{B}, \mathrm{L}) & -(\mathrm{B}) & -(\mathrm{B}, \mathrm{L}) \\ 4+ & + & 4+ & - & - & 3+ \\ 4+ & + & 4+ & 4+ & -(\mathrm{B}, \mathrm{L}) & 3+\end{array}$

and pND161-encoded naphthalene catabolic pathway enzymes were assayed in order to determine the overall regulatory changes that had arisen as a result of the mutations. Naphthalene oxygenase, salicylaldehyde dehydrogenase and salicylate hydroxylase were chosen as representatives of the enzymes which convert naphthalene to catechol. Catechol 2,3-dioxygenase, 2-hydroxymuconic semialdehyde dehydrogenase and 2-hydroxymuconic semialdehyde hydrolase were chosen as representatives of the meta-cleavage pathway enzymes (Table 3).

Growth in the presence of salicylate induced each of the six enzymes in PP1-10(NAH). Benzoate did not elicit any significant increase in the constitutive activity of each enzyme but $m$-toluate appeared to cause partial induction of each enzyme. In other words, the NAHspecified naphthalene oxygenase, salicylaldehyde delhydrogenase, salicylate hydroxylase and initial meta-cleavage pathway enzymes have similar inducer specificities. This result suggested that these enzymes share a regulatory gene.

The observation that PP1-10(pND110) lacked detectable naphthalene oxygenase and salicylaldehyde dehydrogenase activities explains the inability of PPI-10(pND110) to grow on naphthalene (Table 2). Because no naphthalene-utilizing revertants of PP1-10(pND110) could be obtained it is possible that the absence of these activities was the result of a deletion in the NAH plasmid DNA. Comparison with NAH-specified enzyme assay results indicates that the pND110-specified catechol 2,3-dioxygenase, 2-hydroxymuconic semialdehyde dehydrogenase and 2-hydroxymuconic semialdehyde hydrolase all exhibited similar altered inducer specificity. The similarity and simultaneity of these inducer specificity alterations suggests that these enzymes are controlled by one regulatory gene. It appears that salicylate hydroxylase is controlled by the same regulatory gene but since the induction ratio is low compared to the other three enzymes, this enzyme may belong to a different operon.

The pND111-specified catechol 2,3-dioxygenase, 2-hydroxymuconic semialdehyde dehydrogenase and 2-hydroxymuconic semialdehyde hydrolase were constitutive and noninducible in PP1-10(pND111). In contrast, the pND111-specified naphthalene oxygenase, 


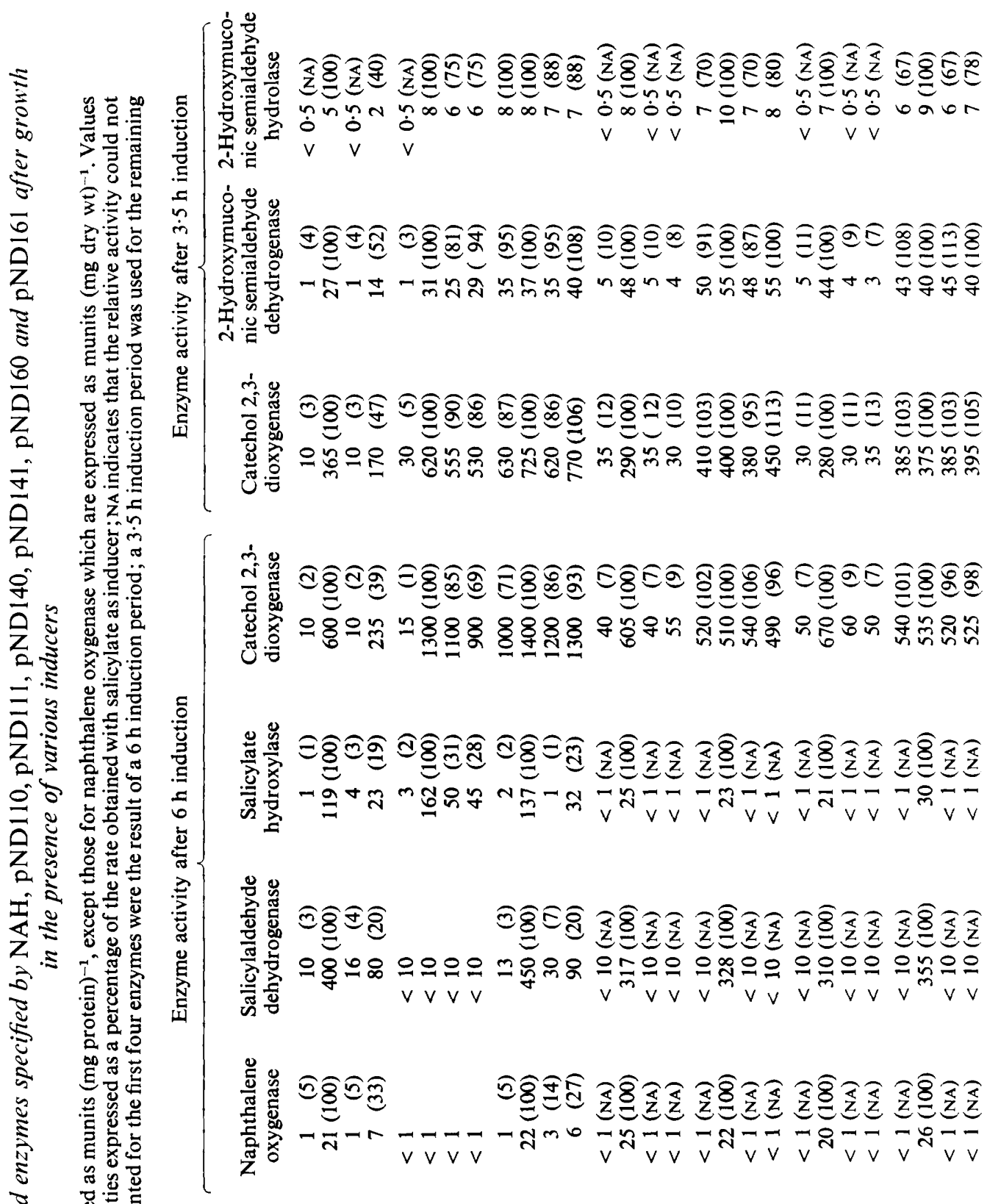

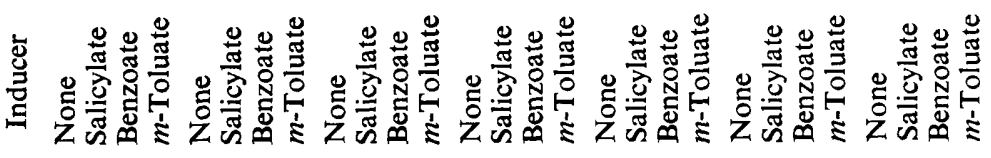

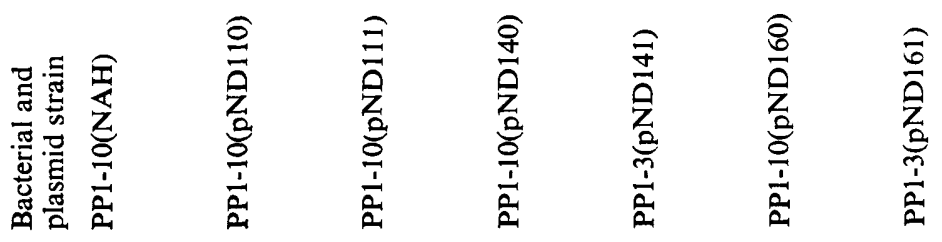


salicylaldehyde dehydrogenase and salicylate hydroxylase did not show any alteration in regulation. They were still inducible in PP1-10(pND111) and exhibited approximately the same inducer specificities and induction ratios as the corresponding NAH-specified enzymes. These observations suggest that the genes specifying the initial meta-cleavage pathway enzymes belong to one operon. The NAH genes which encode the naphthalene catabolic pathway enzymes thus appear to comprise at least two operons, namely the genes specifying naphthalene conversion to catechol and the genes specifying the meta-cleavage pathway.

The pND140 and pND160-encoded naphthalene cxygenase, salicylaldehyde dehydrogenase, salicylate hydroxylase and initial meta-cleavage: pathway enzymes exhibited similar inducer specificities. This suggests that the enzymes share a regulatory gene. Unlike the NAH-encoded system, $m$-toluate appeared unable to cause partial induction of the enzymes assayed.

The mutations in pND141 and pND161 resulted in increased constitutive activity of catechol 2,3-dioxygenase, 2-hydroxymuconic semialdehyde dehydrogenase and 2-hydroxymuconic semialdehyde hydrolase. The first two enzymes showed similar induction ratios in PP1-10(pND140) and in PP1-10(pND160) extracts. The 2-hydroxymuconic semialdehyde hydrolase induction ratios were not calculated because of the lack of detectable activity after growth in the absence of inducer. These results suggest that the pND140 and pND160encoded meta-cleavage pathway enzymes belong to one operon. The pND140 and pND160specified enzymes which convert naphthalene to catechol were not constitutive in PP1-3(pND141) and PP1-3(pND161) indicating that they belong to a separate operon (or operons) from the enzymes of the meta-cleavage pathway.

In summary, these results suggest that the NAH, pND140 and pND160 genes which specify the naphthalene catabolic pathway comprise at: least two operons: the genes specifying the conversion of naphthalene to catechol, and the genes specifying catechol degradation.

The inability of PP1-3(pND141) and PP1-3(pND161) to grow on $m$-toluate was unexpected. The host cell PP1-3 can convert $m$-toluate to 3-methylcatechol and the plasmid-encoded meta-cleavage pathway is produced constitutively. 3-Methylcatechol is degraded through the hydrolase branch of the meta-cleavage pathway. Constitutive activities of 2-hydroxymuconic semialdehyde hydrolase appear to be quite adequate to permit growth when compared to the enzyme activities produced by NAH, pND110 and pND111 which permit PP1-3 harbouring these plasmids to grow on $m$-toluate. Use of $m$-toluate as an inducing agent for PP1-3(pND141) and PP1-3(pND161) did not inhibit or prevent induction of any of the enzymes assayed but it is evident that growth on $m$-toluate could only be obtained as the result of an additional mutation in either PP1-3(pND141) or PP1-3(pND161) (Table 2).

The relative ease with which mutants exhibiting altered control of the naphthalene catabolic pathway could be isolated suggested a reason for the different regulation of naphthalene catabolism reported by Williams et al. $(1975)$ and Barnsley $(1975,1976 a)$ in Pseudomonas $\mathrm{P}_{\mathrm{G}}$ (NCIB 9816). Williams et al. (1975) reported that in this strain growth in the presence of naphthalene induced the enzymes which convert naphthalene to catechol and the enzymes of the meta-cleavage pathway. Growth in the presence of salicylate resulted in induction of salicylate hydroxylase and the ortho-cleavage pathway enzymes. Barnsley $(1975,1976 a)$ reported that in a strain which was also supplied as NCIB 9816 growth in the presence of naphthalene, salicylate or a salicylate anlalogue induced the enzymes which convert naphthalene to catechol but not the meta-cleavage pathway enzymes. Catechol was degraded through the ortho-cleavage pathway in this strain. Barnsley (1976a) also found that in Pseudomonas $\mathrm{P}_{\mathrm{G}}$ (obtained from P. A. Williamis) growth in the presence of naphthalene, salicylate or a salicylate analogue induced the enzymes which convert naphthalene to catechol. However, high constitutive activities of the meta-cleavage pathway enzymes were not obtained in the absence of any aromatic inducers. These activities were much higher 
than the corresponding activities observed by Barnsley (1976a) in NCIB 9816 and by Williams et al. (1975) in Pseudomonas $\mathrm{P}_{\mathrm{G}}$. In other words, the three strains which were originally supplied as NCIB 9816 showed different regulation of naphthalene catabolism.

It is possible that regulation of naphthalene catabolism in these strains is similar to that of the NAH-specified pathway and that in each strain a mutation has altered control of the pathway.

This work was supported by a grant from the Australian Research Grants Committee. R. A. A. was supported by an Australian Commonwealth Postgraduate Scholarship.

\section{REFERENCES}

Austen, R. A. \& Dunn, N. W. (1977a). A comparative study of the NAH and TOL catabolic piasmids in Pseudomonas putida. Australian Journal of Biological Sciences 30, 357-366.

Austen, R. A. \& DunN, N. W. (1977b). Isolation of mutants with altered metabolic control of the NAH plasmid-encoded catechol meta cleavage pathway. Australian Journal of Biological Sciences 30, 583-592.

BARNSLEy, E. A. (1975). The induction of the enzymes of naphthalene metabolism in pseudomonads by salicylate and 2-aminobenzoate. Journal of General Microbiology 88, 193-196.

BARnSLEY, E. A. (1976a). Role and regulation of the ortho and meta pathways of catechol metabolism in pseudomonads metabolising naphthalene and salicylate. Journal of Bacteriology 125, 404 408.

BARNSLEY, E. A. $(1976 b)$. Naphthalene metabolism by pseudomonads: the oxidation of 1,2-dihydroxynaphthalene to 2-hydroxychromene-2-carboxylic acid and the formation of 2-hydroxybenzalpyruvate. Biochemical and Biophysical Research Communications 72, 1116-1121.

Caterall, F. A., Murray, K. \& Williams, P. A. (1971 a). The configuration of the 1,2-dihydroxy1,2-dihydronaphthalene formed in the bacterial metabolism of naphthalene. Biochimica et biophysica acta 237, 361-364.

Caterall, F. A., Sala-Trepat, J. M. \& Williams, P. A. $(1971 b)$. The coexistence of two pathways for the metabolism of 2-hydroxymuconic semialdehyde in a naphthalene-grown pseudomonad. Biochemical and Biophysical Research Communications 43, 463-469.

Chakrabarty, A. M. (1972). Genetic basis of the biodegradation of salicylate in Pseudomonas. Journal of Bacteriology 112, 815-823.

Davies, J. I. \& Evans, W. C. (1964). Oxidative metabolism of naphthalene by soil pseudomonads. Biochemical Journal 91, 251-261.

Dunn, N. W. \& Gunsalus, I. C. (1973). Transmissible plasmid coding early enzymes of naphthalene oxidation in Pseudomonas putida. Journal of Bacteriology 114, 974-979.

Dunn, N. W., DunN, H. M. \& Austen, R. A. (1980). Evidence for the existence of two catabolic plasmids coding for the degradation of naph- thalene. Journal of General Microbiology 117, 529-533.

Jerina, D. M., Daly, J. W., JefFrey, A. M. \& GiBson, D. T. (1971). cis-1,2-Dihydroxy-1,2dihydronaphthalene: a bacterial metabolite from naphthalene. Archives of Biochemistry and Biophysics 142, 394-396.

Murray, K. \& Williams, P. A. (1974). Role of catechol and the methylcatechols as inducers of aromatic metabolism in Pseudomonas putida. Journal of Bacteriology 117, 1153-1157.

Nozaki, M., KagamiYama, $H$. \& Hayaishi, $O$. (1963). Metapyrocatechase. I. Purification, crystallisation and some properties. Biochemische Zeitschrift 338, 582-586.

Sala-Trepat, J. M., Murray, K. \& Williams, P. A. (1972). The metabolic divergence in the metacleavage of catechols by Pseudomonas putida NCIB 10015. European Journal of Biochemistry 28, 347-356.

Shamsuzzaman, K. M. \& Barnsley, E. A. (1974a). The regulation of naphthalene oxygenase in pseudomonads. Journal of General Microbiology 83, 165-170.

Shamsuzzaman, K. M. \& Barnsley, E. A. (1974b). The regulation of naphthalene metabolism in pseudomonads. Biochemical and Biophysical Research Communications 60, 582-589.

White, G. P. \& DunN, N. W. (1977). Apparent fusion of the TOL plasmid with the R91 drug resistance plasmid in Pseudomonas aeruginosa. Australian Journal of Biological Sciences 30, 345-355.

Williams, P. A. \& Murray, K. (1974). Metabolism of benzoate and the methylbenzoates of Pseudomonas putida (arvilla) mt-2: evidence for the existence of the TOL plasmid. Journal of Bacterio$\log y, 120,416-423$.

Williams, P. A., Catterall. F. A. \& Murray, K. (1975). Metabolism of naphthalene, 2-methylnaphthalene, salicylate and benzoate by $P$ seudomonas $\mathrm{P}_{\mathrm{G}}$ : regulation of tangential pathways. Journal of Bacteriology 124, 680-685.

Wong, C. L. \& DunN, N. W. (1974). Transmissible plasmid coding for the degradation of benzoate and $m$-toluate in Pseudomonas arvilla $\mathrm{mt}-2$. Genetical Research 23, 227-232. 